\section{GENE SIGNATURES TO PREDICTION RHEUMATOID} ARTHRITIS DEVELOPMENT

Joyce Lubbers, ${ }^{1}$ Mikael Brink, ${ }^{2}$ Lotte A van de Stadt, ${ }^{3}$ Saskia Vosslamber, ${ }^{14}$ John G Wesseling, ${ }^{1}$ Dirkjan van Schaardenburg, ${ }^{3}$ Solbritt M Rantapaa-Dahlqvist, ${ }^{2}$ Cornelis L Verweij ${ }^{1}$ 'Department of Pathology, VU University Medical Center, Amsterdam, Netherlands; ${ }^{2}$ Department of Public Health and Clinical Medicine, Umeå University, Umeå, Sweden; 3Jan van Breemen institute|Reade, Amsterdam, Netherlands; ${ }^{4}$ Preselect Diagnostics BV i.o., Amsterdam, The Netherlands

\subsection{6/annrheumdis-2011-201231.13}

Background/purpose Early recognition of development of rheumatoid arthritis (RA) allows timely start of treatment. Recently, the authors reported gene signatures in the peripheral blood (PB), involving interferon (IFN) activity and B cell related genes, which are associated with the development of arthritis. The objective of this study is to validate these findings in independent cohorts.

Method The authors analysed IFN-response gene expression in $\mathrm{PB}$ samples from 40 anticitrullinated protein antibodies (ACPA)+/rheumatoid factor (RF)+arthralgia patients from the Amsterdam Reade cohort who are clinically followed for RA development. In addition, $\mathrm{PB}$ mononuclear cells (MCs) of 22 preonset RA, 25 RA patients, and 48 healthy controls (HC) from the Northern Sweden Population Repository (Umeå University) were studied. Fluorescence-activated cell sorting (FACS)-analysis for B cell marker expression was performed on $\mathrm{PB}$ from $87 \mathrm{ACPA}+/ \mathrm{RF}+$ arthralgia patients and $30 \mathrm{HC}$ from the Amsterdam Reade cohort. Quantitative PCR (qPCR) for B cell marker was performed of $45 \mathrm{ACPA}+/ \mathrm{RF}+$ arthralgia patients and six HC from the Amsterdam Reade cohort.

Results The IFN-score (average of seven IFN-response genes) was measured at inclusion in an independent group of ACPA+/ $\mathrm{RF}+$ arthralgia patients at risk for RA $(n=40)$. A total of 19 patients developed arthritis within a median period of 11 months (IOR 9-28). Comparative analysis of IFN-score high and low patients confirmed that the high IFN-score is associated with conversion to RA ( $p=0.025)$. In addition, the authors measured the IFN-score in PBMC from RA and preonset RA patients, and HC from the Northern Swedish Repository. Comparative analyses between the groups revealed that both preonset RA patients as well as RA patients had significantly increased IFN-scores compared to HC (Mann-Whitney U test $p=0.0064$ and $p=0.0075$, respectively). For the analysis of the role of $B$ cells in development of RA the authors analysed the FACS profile of $87 \mathrm{ACPA}+\mathrm{RF}+$ at risk patients at inclusion, of who 22 developed RA within a median period to conversion of 10.5 months (IOR 4.5-13). The results confirmed that low $\mathrm{B}$ cell marker expression is significantly associated with RA conversion $(\mathrm{p}=0.01)$. An interim analysis with $\mathrm{qPCR}$ showed a trend towards the association between decreased $\mathrm{B}$ cell transcript marker and RA conversion $(p=0.0714)$.

Conclusion These results provide evidence for a role of IFNactivity and B cell abundance in the preclinical phase of RA. Further studies are aimed to demonstrate the diagnostic value of these markers.

This research was supported by the Center for Translational Molecular Medicine (CTMM) consortium 'TRACER'. 